\title{
Two-Dimensional FTIR as a Tool to Study the Chemical Interactions within Cellulose-Ionic Liquid Solutions
}

\author{
Kalyani Kathirgamanathan, ${ }^{1}$ Warren J. Grigsby, ${ }^{2,3}$ \\ Jafar Al-Hakkak, ${ }^{3,4}$ and Neil R. Edmonds ${ }^{1}$ \\ ${ }^{1}$ University of Auckland, Auckland 1072, New Zealand \\ ${ }^{2}$ Scion, Rotorua 3010, New Zealand \\ ${ }^{3}$ Biopolymer Network Ltd, Rotorua 3040, New Zealand \\ ${ }^{4}$ Plant \& Food Research, Auckland 1142, New Zealand
}

Correspondence should be addressed to Warren J. Grigsby; warren.grigsby@scionresearch.com

Received 30 September 2014; Accepted 11 December 2014

Academic Editor: Long Yu

Copyright (C) 2015 Kalyani Kathirgamanathan et al. This is an open access article distributed under the Creative Commons Attribution License, which permits unrestricted use, distribution, and reproduction in any medium, provided the original work is properly cited.

In this study two-dimensional FTIR analysis was applied to understand the temperature effects on processing cellulose solutions in imidazolium-based ionic liquids. Analysis of the imidazolium ion $\nu \mathrm{C} 2-\mathrm{H}$ peak revealed hydrogen bonding within cellulose solutions to be dynamic on heating and cooling. The extent of hydrogen bonding was stronger on heating, consistent with greater ion mobility at higher temperature when the ionic liquid network structure is broken. At ambient temperatures a blue shifted $\nu \mathrm{C} 2-\mathrm{H}$ peak was indicative of greater cation-anion interactions, consistent with the ionic liquid network structure. Both cellulose and water further impact the extent of hydrogen bonding in these solutions. The FTIR spectral changes appeared gradual with temperature and contrast shear induced rheology changes which were observed on heating above $70^{\circ} \mathrm{C}$ and cooling below $40^{\circ} \mathrm{C}$. The influence of cellulose on solution viscosity was not distinguished on initial heating as the ionic liquid network structure dominates rheology behaviour. On cooling, the quantity of cellulose has a greater influence on solution rheology. Outcomes suggest processing cellulose in ionic liquids above $40^{\circ} \mathrm{C}$ and to reduce the impacts of cation-anion effects and enhance solubilisation, processing should be done at $70^{\circ} \mathrm{C}$.

This paper is dedicated to the late Professor Allan Easteal who was PhD supervisor, colleague and contributor to the research presented in this paper

\section{Introduction}

The use of ionic liquids for cellulose solubilisation and media for cellulose chemical modification emerged over a decade ago [1]. Since this time a range of ionic liquids have been evaluated to dissolve cellulosic precursors and prepare cellulose fractions, gels, and various regenerated cellulose materials. More recently the application of ionic liquids to dissolve cellulose has progressed to use in pretreatment and isolation of lignocellulosic fractions and feedstocks [2]. Alongside the extensive work on cellulose solubilisation and regeneration, studies have evaluated the processing of ionic liquids containing cellulose typically undertaken as solutions or on gel formation. This has included the rheological properties of the cellulose/ionic liquid solutions which have practical applications for equipment design and processing $[3,4]$. There are many considerations for cellulose/ionic liquid solution properties including viscosity and chemical stability. Cellulose/ionic liquid solution rheology properties are dependent on cellulose concentration and degree of polymerization together with the frequency and shear rate $[5,6]$. Typically studies have revealed cellulose solutions to be shearing thinning and dependent on temperature [5, 7-9]. However, cosolvents or water content can also influence cellulose solution rheology behaviours $[10,11]$. 
The chemistry of cellulose dissolution and processing in ionic liquids has been subject to significant investigation [1]. Hydrogen bonding determines the structures and properties of room-temperature ionic liquids where connections between hydrogen bonds form a network within the liquid $[12,13]$. Hydrogen bonding within the ionic liquid is important to cellulose dissolution as well as the structure and resulting physical properties of the solution or gel. Interactions between the anion and cellulose play an important role in cellulose solvation $[1,14]$. Furthermore, hydrogen bonding and solvation efficiency can determine chemical interactions in ionic liquids and cellulose solutions [15]. We have become interested in processing cellulose in ionic liquids to generate novel nanoscale architectures which require control of cellulose solution properties [16]. The purpose of the current paper is to relate the practical aspects of processing cellulose/ionic liquid solutions to the chemistry and hydrogen bonding networks within these solutions. Primarily we investigate the influence of temperature on solution chemistry and rheology behaviours. Through the use of two-dimensional infrared correlations we relate how the presence of cellulose and water sorption impact these properties. Ultimately the goal is to establish preferred conditions to dissolve and process cellulose in ionic liquids as well as outcomes potentially contributing to understandings of cellulose dissolution by ionic liquids.

\section{Methodology}

2.1. Materials. The ionic liquids 1-butyl-3-methylimidazolium chloride (BMIMCl) and 1-ethyl-3-methylimidazolium acetate (EMIMOAc) were obtained from Sigma Aldrich. Each was dried and distilled under vacuum prior to use. Allyl chloride and N-methylimidazole were obtained from Aldrich and freshly distilled prior to their use. The cellulose used was a Whatman high purity microcrystalline cellulose powder which was poly-dispersed with a molar mass distribution range between $1 \times 10^{4}$ and $3 \times 10^{6}$ and further defined elsewhere [16]. Postprocessing molecular weight analysis was not undertaken given differing conditions were employed $\left(\mathrm{N}_{2}\right.$, air).

2.1.1.1-Allyl-3-methylimidazolium Chloride (AMIMCl) Synthesis. Allyl chloride $(200 \mathrm{~mL})$ was added to N-methylimidazole $(100 \mathrm{~mL})$ in a round bottomed flask as described by Zhang et al. [14]. The mixture was then refluxed under nitrogen for $24 \mathrm{~h}$ with stirring. After cooling any unreacted materials were removed by extraction with ethyl acetate. The residual product was vacuum distilled to give pure AMIMCl as an amber liquid (yield $62 \%$ ). $\mathrm{m} / \mathrm{z}$ calculated: 158.5, found: 158.05 . Refractive index: 1.547 , lit. value: 1.5465 . ${ }^{1} \mathrm{H} \mathrm{NMR} \delta 3.63\left(\mathrm{~N}-\mathrm{CH}_{3}\right), 4.89\left(\mathrm{~N}-\mathrm{CH}_{2}-\mathrm{CH}\right), 5.28\left(\mathrm{~N}-\mathrm{CH}_{2}-\right.$ $\left.\mathrm{CH}=\mathrm{CH}_{2}\right), 6.01\left(\mathrm{~N}-\mathrm{CH}_{2}-\mathrm{CH}=\mathrm{CH}_{2}\right), 7.8-7.7(\mathrm{C} 4 \boldsymbol{H}, \mathrm{C} 5 \boldsymbol{H})$, $9.40(\mathrm{C} 2 \boldsymbol{H})$ ppm. ${ }^{13} \mathrm{C} \mathrm{NMR} \delta 36.0\left(\mathrm{~N}-\mathrm{CH}_{3}\right), 50.9(\mathrm{~N}-$ $\left.\mathrm{CH}_{2} \mathrm{CH}\right), 120.5\left(\mathrm{~N}-\mathrm{CH}_{2} \mathrm{CH}=\mathrm{CH}_{2}\right), 122.4$ (C5), 123.9 (C4), $132.0\left(\mathrm{~N}-\mathrm{CH}_{2}-\mathrm{CH}=\mathrm{CH}_{2}\right), 136.8($ C2 $)$.

2.2. Cellulose Dissolution. Prior to cellulose dissolution, cellulose and each ionic liquid were further dried in a vacuum oven at $65-70^{\circ} \mathrm{C}$ overnight. Cellulose $(2-10 \% \mathrm{w} / \mathrm{w})$ was then weighted into a flask containing ionic liquid. Dissolution of each solution was then carried out by stirring in a sealed flask at elevated temperature $\left(70-90^{\circ} \mathrm{C}\right)$ using an oil bath. Cellulose dissolution was monitored by light microscopy until no more fibrous material was observed. Cellulose solutions were then stored at $35^{\circ} \mathrm{C}$ in a vacuum oven prior to use.

2.3. Rheology. Oscillatory and steady shear measurements were carried out using a Universal Dynamic Rheometer (UDS 200, Paar-Physica, Germany) equipped with an air cooled peltier heating element using a parallel plate geometry (MP $30,25 \mathrm{~mm}, 0^{\circ}$ ) with a gap distance of $0.5 \mathrm{~mm}$. Temperature sweep studies employed a strain of $1 \%$ and an angular frequency of $10 \mathrm{~Hz}$. Heating or cooling was undertaken at a rate of $1^{\circ} \mathrm{C} / \mathrm{min}$.

2.4. Fourier Transform Infrared Spectroscopy (FTIR). FTIR spectra were acquired employing a Thermo Electron Nicolet 8700 FTIR spectrometer. A total of 32 scans were collected in the $650 \mathrm{~cm}^{-1}$ to $4000 \mathrm{~cm}^{-1}$ range with a resolution of $4 \mathrm{~cm}^{-1}$. Variable temperature spectra were collected using a Spectra-Tech Thermal ARK accessory fitted with a $\mathrm{ZnSe}$ crystal trough plate which was flushed with dry air. For heating or cooling spectra, the sample was heated at a rate of $5^{\circ} \mathrm{C} / \mathrm{min}$ and allowed to equilibrate at the set temperature for 5 minutes prior to spectra acquisition.

2.4.1. Two-Dimensional Correlation Analysis. A baseline correction was performed for all spectra in defined wavenumber ranges before calculation of the $2 \mathrm{D}$ correlation. A reference spectrum was chosen as the average spectrum of all the spectra selected for correlation analysis. A generalised twodimensional correlation analysis was performed using the $2 \mathrm{D}$ spectral correlation analysis solution of the OMNIC spectroscopic software (version 1.1.0, Thermo Electron Cooperation Spectra Corr). In the 2D contour maps, the red coloured regions are defined as the positive correlation intensities with blue-coloured region the corresponding negative correlation intensities.

\section{Results and Discussion}

In this study cellulose was dissolved in ionic liquids with concentrations varying from 1 to $10 \% \mathrm{w} / \mathrm{w}$. Of the three ionic liquids used, cellulose solutions prepared with 1butyl-3-methylimidazolium chloride (BMIMCl) tended to have relatively higher viscosity than using 1-allyl-3methylimidazolium chloride (AMIMCl) with 1-ethyl-3methylimidazolium acetate (EMIMOAc) solutions proving to be the least viscous. Cellulose concentrations up to $7 \%$ were used in rheology assessments, but, practically, lower concentration cellulose solutions were easier to handle and process as noted by others $[5,17,18]$. The cellulose solutions were also prepared to avoid moisture sorption, but rheology and infrared evaluations were conducted in ambient conditions to mimic typical processing environments. 


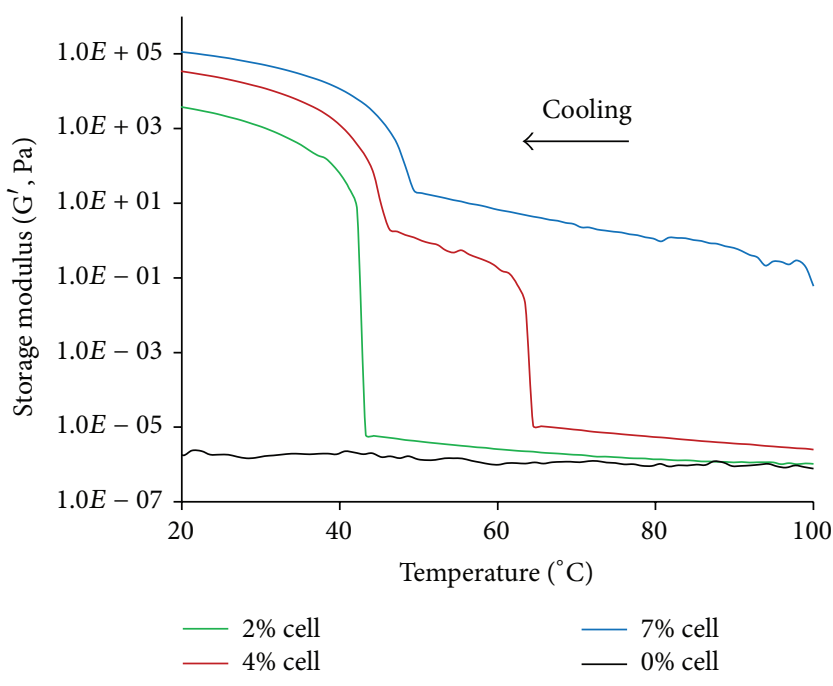

(a)

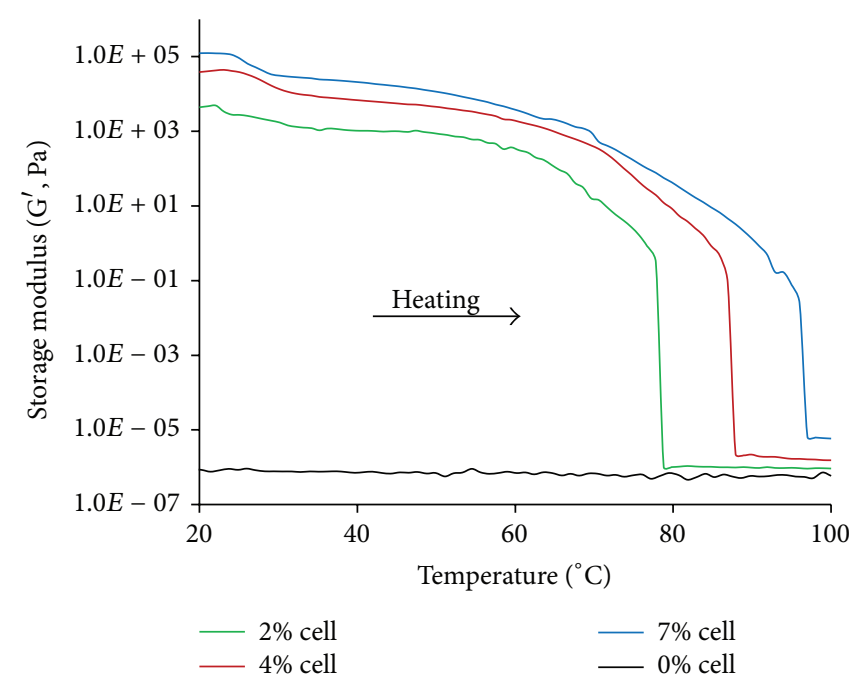

(b)

FIGURE 1: Effect of cellulose concentration of storage modulus with temperature for AMIMCl solutions on cooling (a) and heating (b). Pure AMIMCl (black), 2\% cellulose (green), 4\% cellulose (red), and 7\% cellulose (blue) solutions.

This led to the hygroscopic cellulose solutions and respective ionic liquids readily adsorbing moisture during analyses.

3.1. Rheology of Ionic Liquids and Cellulose Solutions. Rheological behaviours of ionic liquids and cellulose solutions were assessed by oscillatory shear experiments. Shear behaviour profiles of AMIMCl solutions with varying cellulose content are given in Figure 1. In these profiles, sample solutions were analysed by initially cooling from $100^{\circ} \mathrm{C}$ to minimise any effects of solution hygroscopicity on rheology. Analysis revealed the $2 \%$ cellulose solution had very low storage modulus $\left(\mathrm{G}^{\prime}\right)$ at $100^{\circ} \mathrm{C}$ which was observed to increase at ca. $40^{\circ} \mathrm{C}$ followed by a minor $\mathrm{G}^{\prime}$ increase with further cooling to $20^{\circ} \mathrm{C}$. On cooling the $4 \%$ cellulose solution, two transitions were observed with the first at $c a .65^{\circ} \mathrm{C}$ followed by a second at $c a .45^{\circ} \mathrm{C}$. At $7 \%$ cellulose content, the solution has greater storage modulus at high temperatures and, on cooling, an increase was observed at $50^{\circ} \mathrm{C}$ with the profile being similar to both $2 \%$ and $4 \%$ solutions on further cooling to $20^{\circ} \mathrm{C}$. On heating, all samples have relatively similar $\mathrm{G}^{\prime}$ profiles to $\mathrm{ca}$. $60^{\circ} \mathrm{C}$ where each exhibited a transition onset with significant loss in $\mathrm{G}^{\prime}$ between 70 and $100^{\circ} \mathrm{C}$. This transition was observed at $77^{\circ} \mathrm{C}, 86^{\circ} \mathrm{C}$, and $96^{\circ} \mathrm{C}$ for the $2 \%, 4 \%$, and $7 \%$ cellulose solutions, respectively. Pure AMIMCl did not show these shear behaviours on cooling or heating. Interestingly, a $2 \%$ cellulose solution prepared with 1-butyl-3-methylimidazolium chloride (BMIMCl) showed comparable shear behaviour as that observed with AMIMCl (see Supplementary Material available online at http://dx.doi.org/10.1155/2015/958653).

A dependency of cellulose content in AMIMCl solution shear behaviour was also evident in viscosity profiles of these solutions (Figure 2). Unsurprisingly, higher cellulose content gave greater viscosity $[5,17,18]$ with this more distinguished at higher temperature. On cooling from 100 to $20^{\circ} \mathrm{C}$, samples show a steady, consistent viscosity increase. However, on heating, samples initially have comparable viscosities, but above $50^{\circ} \mathrm{C}$ viscosity was distinguished by higher cellulose content. This shear thinning viscosity behaviour is consistent with reportedly pseudoplastic AMIMCl solutions at $10-25 \%$ cellulose content [17]. However, discontinuities in viscosity profiles are also evident in Figure 2 which can be related to temperature transitions observed in rheology profiles (Figure 1). On cooling below $50^{\circ} \mathrm{C}$ the discontinuity was associated with an increase in viscosity evident across the three cellulose solutions, but not with pure AMIMCl. Similarly, on heating above $50^{\circ} \mathrm{C}$ each solution showed an abrupt increase in viscosity compared to pure $\mathrm{AMIMCl}$. This discontinuity was at $55^{\circ} \mathrm{C}$ for the $2 \%$ cellulose solution compared to $70^{\circ} \mathrm{C}$ for $7 \%$ cellulose content, consistent with the observed onset of the transition and shear behaviours on heating (Figure 1).

Rheology evaluation of EMIMOAc cellulose solutions also revealed shear behaviour dependencies with temperature and cellulose content (Figure 3). On cooling 4\% and 7\% cellulose solutions there appeared minimal effect on rheological behaviours above $50^{\circ} \mathrm{C}$. Cooling below $40^{\circ} \mathrm{C}$ gave an increase in $\mathrm{G}^{\prime}$ with transitions observed at $25^{\circ} \mathrm{C}$ and $35^{\circ} \mathrm{C}$ for the $4 \%$ and $7 \%$ solutions, respectively. On heating, both solutions show a decrease in $\mathrm{G}^{\prime}$ above $\mathrm{ca} .40^{\circ} \mathrm{C}$ with a significant loss in $\mathrm{G}^{\prime}$ between $55^{\circ} \mathrm{C}(4 \%)$ and $70^{\circ} \mathrm{C}(7 \%)$ which was comparable to that observed for $\mathrm{AMIMCl}$ solutions (Figure 1). In contrast, the 2\% cellulose EMIMOAc solution maintained a relatively static $\mathrm{G}^{\prime}$ profile on cooling to $20^{\circ} \mathrm{C}$, being similar to the behaviour of pure EMIMOAc. This was similarly the case on heating both pure EMIMOAc and the $2 \%$ cellulose solution. Also perhaps an emerging influence of moisture on rheology profiles is evident in Figure 3. Cooling EMIMOAc solutions revealed decreases in $\mathrm{G}^{\prime}$ values consistent with ionic liquid hygroscopicity with water known to impact EMIMOAc rheological properties [11]. 


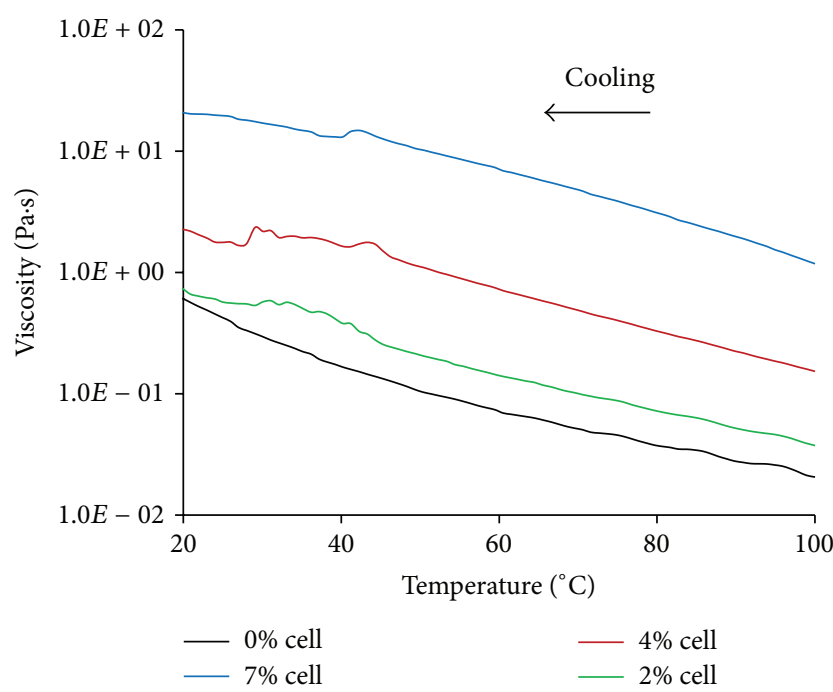

(a)

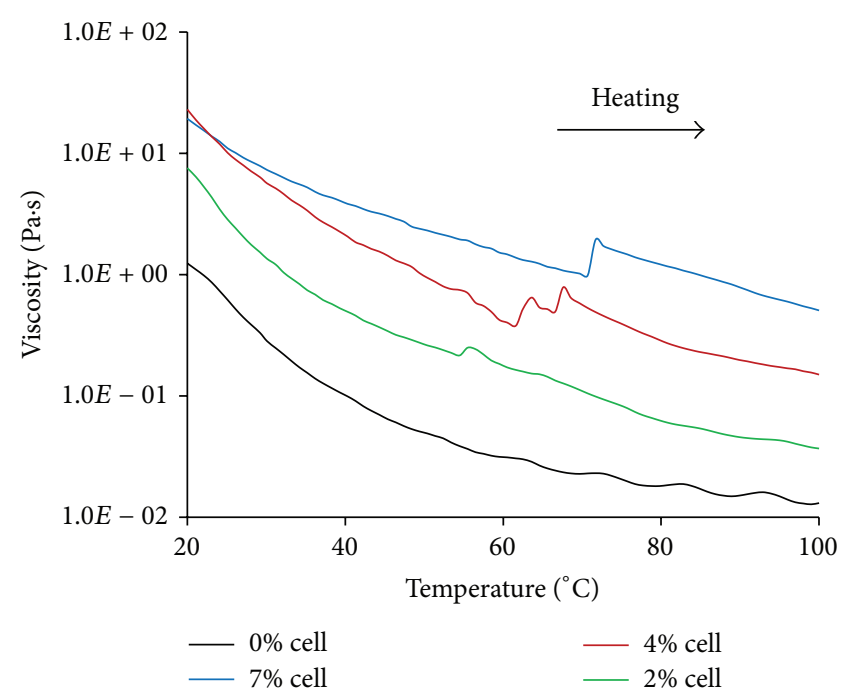

(b)

FIGURE 2: Viscosity profiles for cellulose in AMIMCl solution on cooling (a) and heating (b). Pure AMIMCl (black), 2\% cellulose (green), 4\% cellulose (red), and $7 \%$ cellulose (blue) solutions.

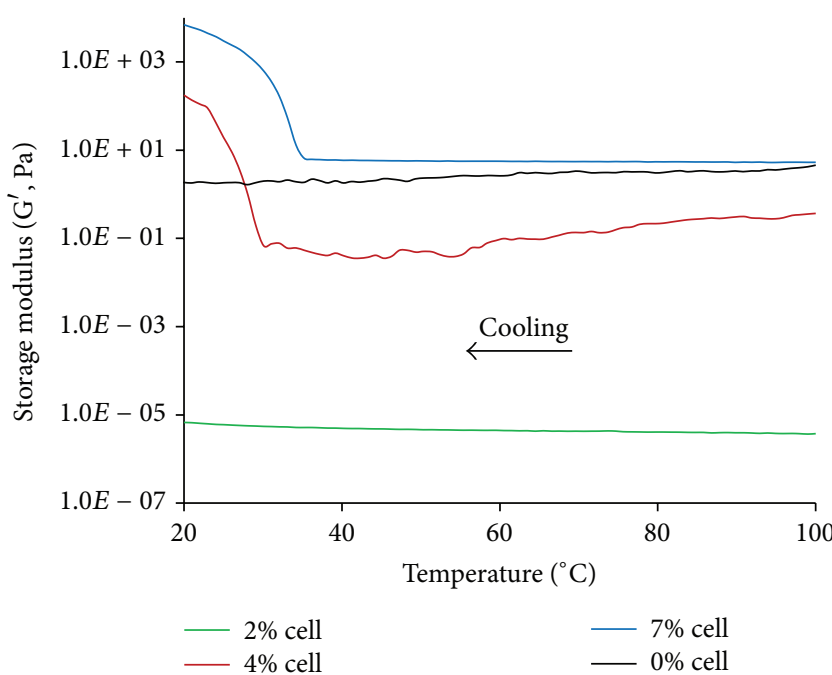

(a)

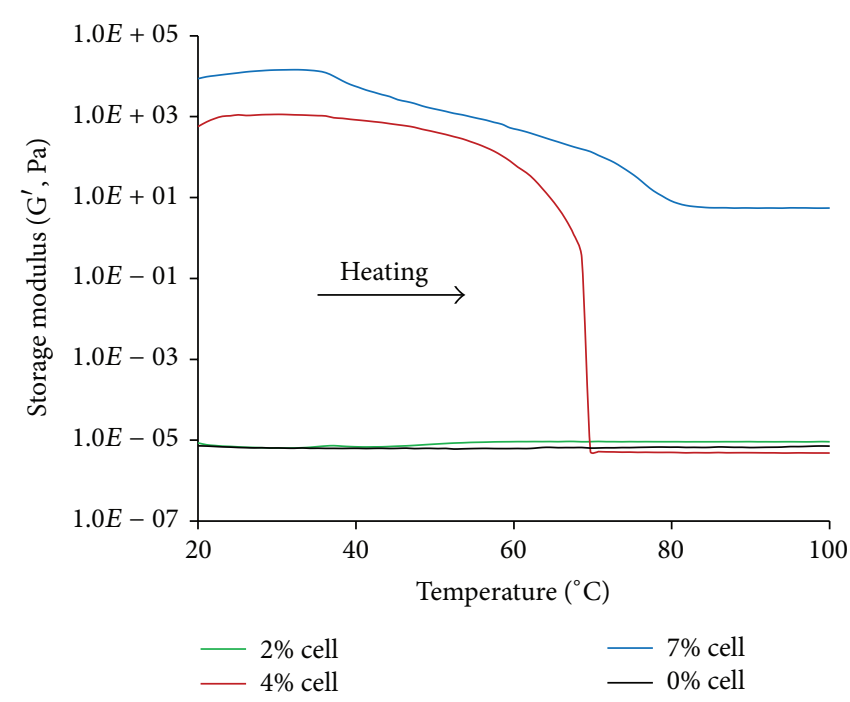

(b)

FIGURE 3: Effect of cellulose concentration of storage modulus with temperature for EMIMOAc solutions on cooling (a) and heating (b). Pure EMIMOAc (black), $2 \%$ cellulose (green), $4 \%$ cellulose (red), and $7 \%$ cellulose (blue) solutions.

3.2. FTIR Spectroscopy Analysis. To assess the effect of temperature on ionic liquid networks and observed rheological properties, infrared analysis was used to gain insights into the extent of hydrogen bonding. FTIR spectra were acquired for cellulose solutions at key temperatures between 20 and $100^{\circ} \mathrm{C}$ on first heating and then cooling samples (Figure 4). Generally, for each cellulose solution, the spectra were relatively similar to that obtained for the respective pure ionic liquid (Supplementary Material). The spectrum of $2 \%$ cellulose in AMIMCl solution shows key peaks at 3050, 2965, 1570 and $1165 \mathrm{~cm}^{-1}$ attributable to $\nu \mathrm{C} 2-\mathrm{H}, \nu \mathrm{C}-\mathrm{H}$ methyl, $\nu \mathrm{C}-$ $\mathrm{N}$, and $\delta \mathrm{C}-\mathrm{H}$, respectively [15]. These peaks, representative of the imidazolium ion, were also common to BMIMCl and EMIMOAc solutions. Other relevant identifying peaks include $3100(\nu \mathrm{C}-\mathrm{H}), 1645(\nu \mathrm{C}=\mathrm{C})$, and $1420 \mathrm{~cm}^{-1}(\delta \mathrm{CH})$. Peaks attributable to cellulose such as the key cellulose $\nu \mathrm{C}-$ $\mathrm{O}-\mathrm{C}$ peak at $1020 \mathrm{~cm}^{-1}$ were difficult to determine, perhaps reflective of the low concentration in the ionic liquid [19].

Analysis of cellulose in AMIMCl spectra revealed the $\nu \mathrm{C} 2-\mathrm{H}\left(3050 \mathrm{~cm}^{-1}\right)$ and alkyl $\left(\nu \mathrm{C}-\mathrm{H}, 2980 \mathrm{~cm}^{-1}\right)$ peaks were dynamic on both heating and cooling (Figure 4). Each temperature step in Figure 4 was selected to encompass temperatures incorporating rheological transitions evident in Figure 1 . With the $\nu \mathrm{C} 2-\mathrm{H}$ peak sensitive to hydrogen bonding 


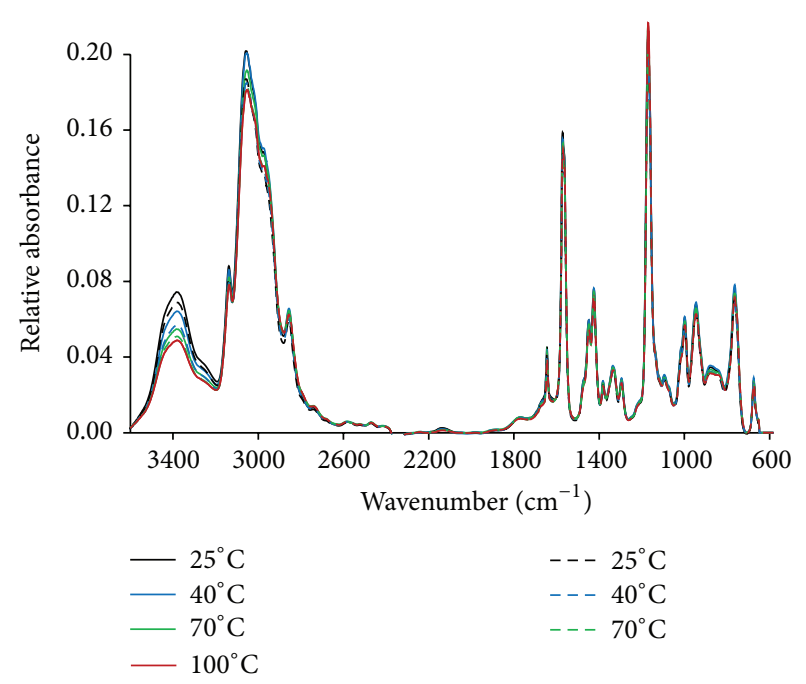

(a)

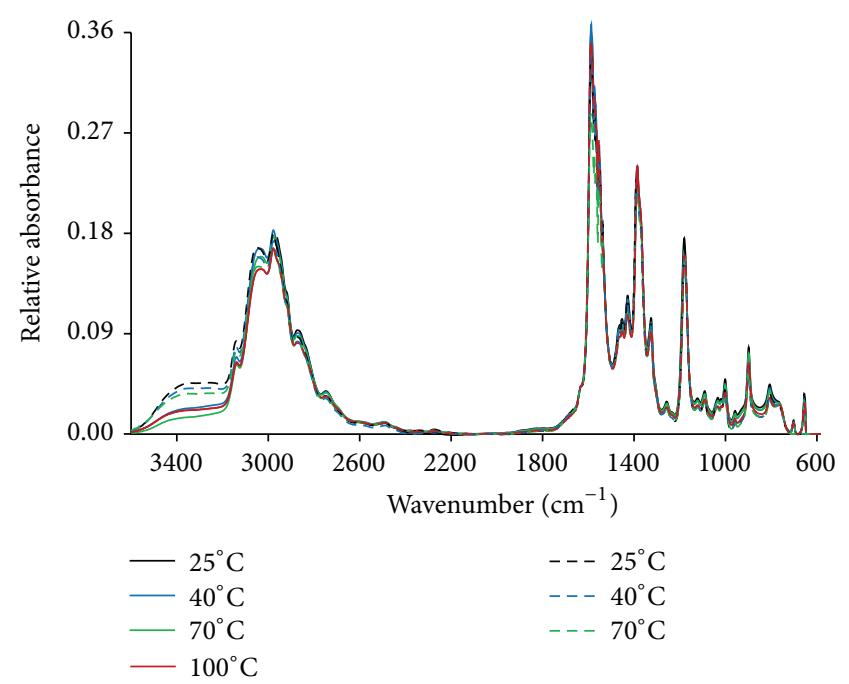

(b)

FIGURE 4: FTIR spectra of 2\% cellulose solutions in AMIMCl (a) and EMIMOAc (b) solutions. Spectra obtained on heating (-) from $25^{\circ} \mathrm{C}$ to $100^{\circ} \mathrm{C}$ and then on cooling (- - ) to $25^{\circ} \mathrm{C} .25^{\circ} \mathrm{C}$ (black), $40^{\circ} \mathrm{C}$ (blue), $70^{\circ} \mathrm{C}$ (green), and $100^{\circ} \mathrm{C}$ (red).

[15], Figure 4 provides evidence for changes in the extent of imidazolium ion hydrogen bonding with temperature. An increase in hydrogen bonding causes the lengthening of the $\mathrm{C} 2-\mathrm{H}$ bond with the $\nu \mathrm{C} 2-\mathrm{H}$ stretching peak moving to lower wavenumbers (red shift). In contrast, other AMIMCl (cellulose solution) peaks between 700 and $1700 \mathrm{~cm}^{-1}$ including the allyl group (1645 and $1420 \mathrm{~cm}^{-1}$ ) remain relatively unaffected on heating or cooling. In comparing the relative intensity changes of imidazolium ion peaks to that observed with the pure ionic liquid (Supplementary material), these appear relatively less than observed for the cellulose solution. Despite attempts to exclude moisture, evident in Figure 4 were spectra showing the strong $\nu \mathrm{O}-\mathrm{H}$ stretching band $\left(3500-3200 \mathrm{~cm}^{-1}\right)$ to be dynamic on both heating and cooling. This reflects sample hygroscopicity, where the $\nu \mathrm{O}-\mathrm{H}$ peak was indicating water loss on heating with water sorption evident on cooling. A comparison of FTIR obtained with pure AMIMCl also revealed similar hygroscopicity with water sorption also evident on both heating and cooling. Analysis of the $\mathrm{BMIMCl}$ cellulose solution revealed spectral changes of the imidazolium ion peaks were similar to AMIMCl, but the $\nu \mathrm{O}-$ $\mathrm{H}$ absorption was observed to increase both on heating and cooling (Supplementary Material).

Infrared spectroscopic evaluation of the EMIMOAc cellulose solution revealed spectral changes were relatively more responsive to heating and cooling than AMIMCl solution (Figure 4). Imidazolium ion $\nu \mathrm{C}-\mathrm{H}$ peaks at 2990 and $2970 \mathrm{~cm}^{-1}$ decrease in intensity with higher temperature. Furthermore, this change in peak intensity was relatively greater with the cellulose solution than for pure EMIMOAc (Supplementary Material). Dynamic EMIMOAc peaks were also observed between 700 and $1650 \mathrm{~cm}^{-1}$ attributable to the acetate anion $\left(1590\right.$ and $\left.1380 \mathrm{~cm}^{-1}\right)$. Analysis of the broad $\nu \mathrm{O}_{-}$ $\mathrm{H}$ peak revealed the presence of water to remain relatively static on heating but increase in intensity upon cooling, which was similarly the case for pure EMIMOAc (Supplementary Material).

Infrared analysis revealed imidazolium ion peaks in both AMIMCl and EMIMOAc cellulose solutions to be dynamic on heating and cooling. There were changes to both peak shifts and intensities indicating that temperature was influencing the hydrogen bonding networks within both ionic liquids. Furthermore, when compared with pure ionic liquids the presence of cellulose appeared to also impact the relative intensity of these changes. However, the presence of water also proved to complicate this interpretation, with water known to influence hydrogen bonding and cellulose dissolution in ionic liquids [11]. To further distinguish temperature and water influences on ionic liquid hydrogen bonding two-dimensional correlation spectroscopy (2D FTIR) analysis was undertaken. Synchronous and asynchronous spectra generated from simulated spectra gave positive (red) and negative (blue) correlation squares for FTIR peak (band) shift and intensity changes (Figures 5 to 7 and Supplementary Material). Typically, both heating and cooling spectra of pure ionic liquids and cellulose solutions by 2D FTIR show strong cross peaks associated with $\nu \mathrm{O}-\mathrm{H}$ and $\nu \mathrm{C} 2-\mathrm{H}$ peaks, evident as correlation squares (Figure 5).

Two-dimensional correlation FTIR analysis revealed the synchronous spectrum of the cellulose solution in $\mathrm{AMIMCl}$ during heating (Figure 6) was similar to the synchronous spectrum of pure AMIMCl during cooling (Supplementary Material). On heating, the cellulose solution has a broad, inphase autopeak for $\nu \mathrm{O}-\mathrm{H}\left(3600\right.$ to $\left.3200 \mathrm{~cm}^{-1}\right)$ and $\nu \mathrm{C} 2-\mathrm{H}$ peaks. The autocorrelation peak $(\nu \mathrm{C} 2-\mathrm{H})$ was at $3072 \mathrm{~cm}^{-1}$ for the cellulose solution whereas in the pure AMIMCl cooling spectrum it was at $3093 \mathrm{~cm}^{-1}$. This indicated water and potentially cellulose even at $2 \%$ concentration was influencing hydrogen bonding of the imidazolium ion within the solution. Moreover, other $v \mathrm{C}-\mathrm{H}$ peaks were also impacted 


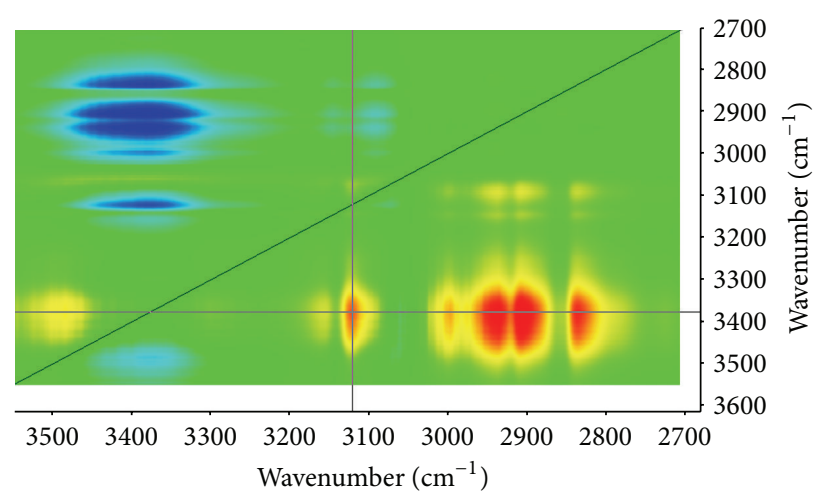

FIGURE 5: Two-dimensional FTIR correlation analysis for $2 \%$ cellulose in AMIMCl solution. Asynchronous spectrum on heating. Spectral range from 2700 to $3600 \mathrm{~cm}^{-1}$.

in the cellulose solution, whereas for pure AMIMCl only the $\nu \mathrm{C}-\mathrm{H}$ at $2937 \mathrm{~cm}^{-1}$ peak was affected (Supplementary Material). In the case of spectra obtained on cooling (Figure 5), the synchronous spectrum of this cellulose solution was similar to that for heating perhaps reflective of temperature effects and similar water content observed on heating and cooling (Figure 4). However, any alkyl $\nu \mathrm{C}-\mathrm{H}$ cross peaks with the $\nu \mathrm{O}-\mathrm{H}$ region (3500 to $3100 \mathrm{~cm}^{-1}$ ) were not developed for this solution during cooling.

In the corresponding asynchronous heating spectrum for the cellulose AMIMCl solution (Figure 5), out of phase cross peaks were developed for the $\nu \mathrm{C}-\mathrm{H}$ alkyl vibrations and imidazolium $\nu \mathrm{C} 4-\mathrm{H}$ and $\nu \mathrm{C} 5-\mathrm{H}$ peaks with $\nu \mathrm{O}-\mathrm{H}$. This indicated the intensities of two spectral features change out of phase with each other and that these differing functional groups were experiencing different effects from heating. No asynchronous cross peaks were observed between $\nu \mathrm{O}-\mathrm{H}$ and $\nu \mathrm{C} 2-\mathrm{H}$ peaks. This contrasts the asynchronous spectrum of pure AMIMCl which showed cross peaks between $\nu \mathrm{O}-\mathrm{H}$ and $\nu \mathrm{C} 2-\mathrm{H}$ (Supplementary Material). In this latter case, the cross peaks observed between $\nu \mathrm{O}-\mathrm{H}$ and $\nu \mathrm{C} 2-$ $\mathrm{H}$ were observed in both the pure AMIMCl synchronous and asynchronous spectrums indicating these two changes were not occurring simultaneously, but were either delayed or accelerated. These results were suggestive of both water and temperature influencing imidazolium ion hydrogen bonding with the asynchronous correlations suggesting the presence of cellulose may also impact hydrogen bonding networks given emergence of $\mathrm{C} 4-\mathrm{H}$ and $\mathrm{C} 5-\mathrm{H}$ cross peaks.

Two-dimensional correlation spectroscopy of the EMIMOAc cellulose solution revealed positive cross peaks at 3089 and $2981 \mathrm{~cm}^{-1}$ and a relative absence of interaction with the $\nu \mathrm{O}-\mathrm{H}$ region in the synchronous spectrum on heating (Figure 7, Supplementary Materials). No cross peaks were observed in the asynchronous spectrum of the heating spectra in this region. This suggests water was not contributing to any imidazolium ion hydrogen bonding differences in EMIMOAc solution on heating. In contrast, on cooling, autopeaks were observed for $3080 \mathrm{~cm}^{-1}$ and the $\nu \mathrm{O}-\mathrm{H}$ region with an absence of any correlation peak at $2981 \mathrm{~cm}^{-1}$. This was also the case for pure EMIMOAc in which there was a strong autopeak at $3070 \mathrm{~cm}^{-1}$ and the $\nu \mathrm{O}-\mathrm{H}$ region compared to a reduced prominence of the $2978 \mathrm{~cm}^{-1}$ peak. Unlike the cellulose solution, the asynchronous cooling spectrum of pure EMIMOAc (Supplementary Material) has cross peaks at $3030 \mathrm{~cm}^{-1}$ and $2960 \mathrm{~cm}^{-1}$ with the $3330 \mathrm{~cm}^{-1}$ band indicative of water interactions. Collectively, this shows, on cooling, that water also had an effect on hydrogen bonding within EMIMOAc solution. Moreover, this was consistent with the increasing presence of water in this sample on cooling (Figure 4).

With the presence of an acetate anion, the carbonyl absorption of EMIMOAc was also analysed by 2D FTIR to determine the extent of any cation-anion hydrogen bonding in EMIMOAc solution (Figure 7). Analysis of the cellulose solution revealed cross peaks of the anion $\left(1500-1600 \mathrm{~cm}^{-1}\right)$ with $\nu \mathrm{C}-\mathrm{H}$ and $\nu \mathrm{O}-\mathrm{H}$ peaks which increase on heating and lessen during cooling. Similarly, for pure EMIMOAc the band at $1602 \mathrm{~cm}^{-1}$ was correlated with the $\nu \mathrm{O}-\mathrm{H}$ peak but was decreasing with both the $\nu \mathrm{C} 2-\mathrm{H}\left(3030 \mathrm{~cm}^{-1}\right)$ and $\nu \mathrm{C}-\mathrm{H}\left(2960 \mathrm{~cm}^{-1}\right.$, alkyl) peaks (Supplementary Material). These results suggest that the anion is interacting with the cation $\mathrm{C} 2 \mathrm{H}$ and methyl group during heating, but only with the $\mathrm{C} 2 \mathrm{H}$ on cooling. Figure 7 shows contrasting behaviour of this carbonyl absorption during cooling together with a cross peak between the $\nu \mathrm{O}-\mathrm{H}$ and $\nu \mathrm{C} 2-\mathrm{H}$ at $3086 \mathrm{~cm}^{-1}$. This provides evidence that the acetate carbonyl $\left(1602 \mathrm{~cm}^{-1}\right)$ is hydrogen-bonded with water and also involved in hydrogen bonding with the imidazolium $\nu \mathrm{C} 2-\mathrm{H}$, particularly at lower temperatures consistent with network structure formation [20]. In comparing 2D FTIR analysis for the cellulose solution and pure EMIMOAc, their similarity suggests, at $2 \%$, the cellulose content may not impact hydrogen bonding networks within the ionic liquid. This finding was also consistent with the $2 \%$ cellulose content having no impact on the rheology profile (Figure 3).

3.3. Discussion. It was evident in FTIR analysis that temperature together with water sorption due to ionic liquid hygroscopicity was influencing the interactions and hydrogen bonding of the imidazolium cation. Water can play a significant role in cellulose dissolution in ionic liquids in addition to impacting hydrogen bonding networks in the ionic liquid [11, 21]. In this study $2 \mathrm{D}$ FTIR has revealed temperature can also influence hydrogen bonding networks within the ionic liquids which may manifest in observed rheology profiles. A shift in the $\nu \mathrm{C} 2-\mathrm{H}$ peak is an indication to the extent of hydrogen bonding [15] with $\mathrm{C} 2-\mathrm{H}$ bond lengthening contributing a red shift to lower wavenumbers. For cellulose in AMIMCl solution the $\nu \mathrm{C} 2-\mathrm{H}$ absorption was at $3072 \mathrm{~cm}^{-1}$ during heating, but increased to $3093 \mathrm{~cm}^{-1}$ on cooling (Figure 4). This was similarly the case in BMIMCl solution with the $\nu \mathrm{C} 2-\mathrm{H}$ absorption at $3040 \mathrm{~cm}^{-1}$ on heating and increasing to $3087 \mathrm{~cm}^{-1}$ on cooling (Supplementary Material). This indicated hydrogen bonding of imidazolium ion $\mathrm{C} 2-\mathrm{H}$ was stronger on heating consistent with greater 


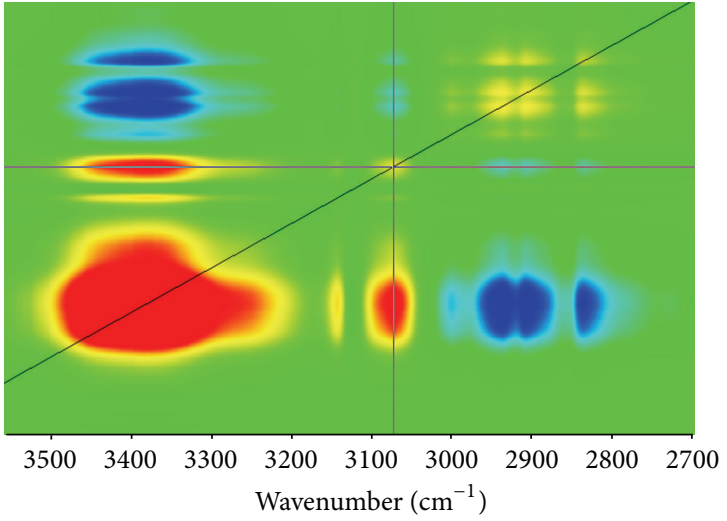

(a)

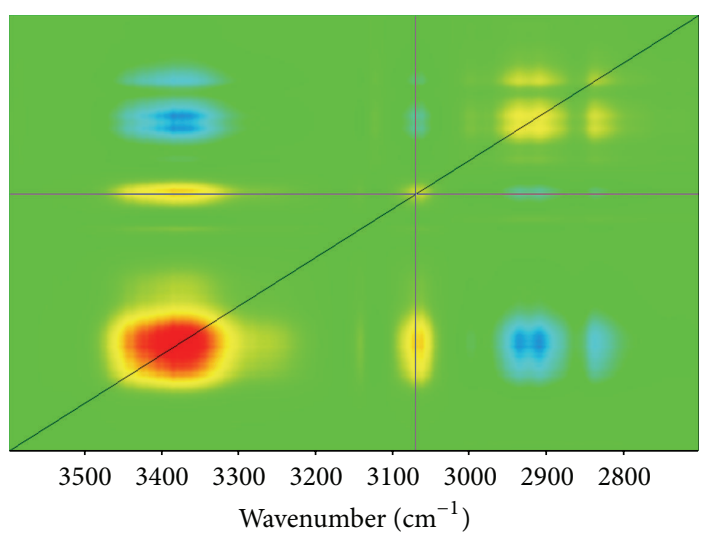

(b)

FIgURE 6: Two-dimensional FTIR correlation analysis of cellulose in AMIMCl solution. Synchronous spectrum on heating (a) and cooling (b). Spectral range 2700 to $3600 \mathrm{~cm}^{-1}$.

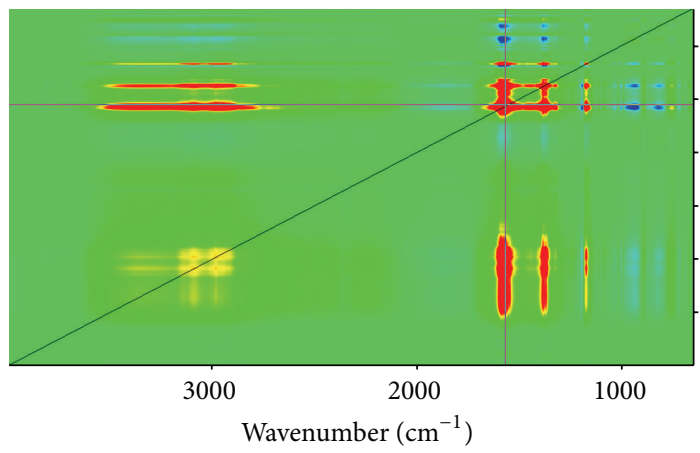

(a)

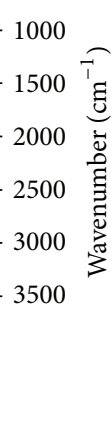

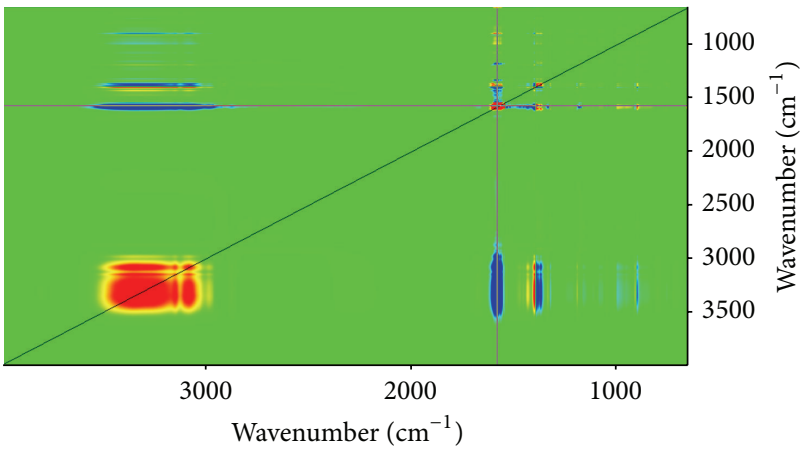

(b)

FIgURE 7: Two-dimensional FTIR correlation analysis of cellulose in EMIMOAc solution. Full spectrum range $\left(400\right.$ to $\left.4000 \mathrm{~cm}^{-1}\right)$ synchronous spectra on heating (a) and cooling (b).

ion mobility at higher temperature. At ambient temperature, there were more cation-anion interactions with the $\nu \mathrm{C} 2-$ $\mathrm{H}$ frequency blue shifted. Also consistent with heating and cooling effects were other $\nu \mathrm{C}-\mathrm{H}$ peak changes indicating the alkyl groups have greater rotational and vibrational freedom at higher temperature when the ionic liquid network structure is broken. FTIR results suggest the higher water contents on cooling enabled water to interact more contributing to a weaker imidazolium-anion interaction and $\nu \mathrm{C} 2-\mathrm{H}$ peak shift. Furthermore, the presence of cellulose in $\mathrm{AMIMCl}$ solution also induced changes in the imidazolium $\nu \mathrm{C}-\mathrm{H}$ absorptions which were not observed in the pure ionic liquid. 2D FTIR suggests cellulose may have minimised the water influence on hydrogen bonding, given differences observed between out of phase cross peaks on heating and cooling (Figure 6).

With EMIMOAc, the $\nu \mathrm{C} 2-\mathrm{H}$ peak of pure EMIMOAc was at $3030 \mathrm{~cm}^{-1}$ during heating and blue shifted to $3070 \mathrm{~cm}^{-1}$ during cooling suggesting temperature similarly influenced the extent of imidazolium cation hydrogen bonding as established for AMIMCl. However, cellulose in EMIMOAc solution contributed to a narrower range in the $\nu \mathrm{C} 2-\mathrm{H}$ peak shift (3080-3089 $\left.\mathrm{cm}^{-1}\right)$ indicating a relatively minimal influence on $\nu \mathrm{C} 2-\mathrm{H}$ hydrogen bonding due to temperature. Moreover, results show the anion to be interacting with $\mathrm{C} 2 \mathrm{H}$ together with other imidazolium $\mathrm{C}-\mathrm{H}$ and methyl groups. Potentially this indicates differences in the extent of interactions between the imidazolium ion and acetate and chloride anions in cellulose solutions with EMIMOAc and AMIMCl, respectively. The $\nu \mathrm{OH}$ peak also contributed a dominant influence on hydrogen bonding due to water sorption on cooling.

FTIR spectra show a gradual change in imidazolium ion hydrogen bonding between 25 and $100^{\circ} \mathrm{C}$, on both heating and cooling. At lower temperatures there were closer interactions between cations and anions indicative of a network structure in the ionic liquids. The shear applied to the ionic liquid solutions was sufficient to break this network, with this observed as transitions under shear at key temperatures in Figures 1 and 3. These transitions resulted in significant inflexions in rheology storage modulus values which were not distinguished by FTIR at these temperature steps, perhaps as 
FTIR was undertaken without solution shear. Furthermore, there was a rheological hysteresis evident between heating and cooling. With decreasing temperature there is apparent super cooling and gel formation [1] leading to slower network organisation within the liquid, observed below $40^{\circ} \mathrm{C}$. However, on heating, initially the ionic liquid network structure is greater and the effect of shear not evident until a higher temperature $\left(50-70^{\circ} \mathrm{C}\right)$, being common to both ionic liquids (Figures 1 and 3). The presence of cellulose increases the ionic liquid viscosity (Figure 2), but has minimal effect on initial heating (Figures 1 and 3 ) as the ionic liquid network structure is dominant. Only on cooling and gel formation was the presence and quantity of cellulose observed to impact rheology. Moreover, given the impact of cellulose observed by 2D FTIR it can be expected cellulose plays an increasing role in hydrogen bonding in AMIMCl at higher concentrations whereas in EMIMOAc any impact of cellulose was observed at $\geq 4 \%$ concentration.

\section{Conclusion}

Oscillatory shear experiments reveal a dependency of temperature and cellulose content on rheology profiles of AMIMCl, BMIMCl and EMIMOAc cellulose solutions which also manifest in viscosity profiles on heating and cooling. Use of two-dimensional FTIR shows dynamic hydrogen bonding between the imidazolium cation and anion on heating and cooling which was also impacted by the presence of cellulose and moisture sorption. A red shift of the imidazolium $\nu \mathrm{C} 2-$ $\mathrm{H}$ peak on heating indicated hydrogen bonding of the cation was stronger consistent with greater ion mobility and loss of the ionic network structure with temperature. These FTIR spectral changes appeared gradual with temperature and contrast shear induced rheology changes which were observed on heating above $70^{\circ} \mathrm{C}$ and cooling below $40^{\circ} \mathrm{C}$. The presence of cellulose increases ionic liquid solution viscosity, but this was not distinguished in solution rheology on initial heating as the ionic liquid network structure dominates. On cooling, the quantity of cellulose has a greater influence on solution rheology with this also expected to influence the processing of cellulose solutions at temperature. Practically, the results of this study suggest the processing of cellulose in ionic liquids to be undertaken above $40^{\circ} \mathrm{C}$ and, to reduce the impacts of cation-anion effects and enhance ionic liquid solubilisation, processing should be done at $70^{\circ} \mathrm{C}$.

\section{Conflict of Interests}

The authors declare that there is no conflict of interests regarding the publication of this paper.

\section{Acknowledgments}

Kalyani Kathirgamanathan would like to thank the Biopolymer Network Ltd for financial support and scholarship stipend. The work presented in this study was supported through funding provided through the New Zealand Ministry of Business, Innovation and Employment.

\section{References}

[1] H. Wang, G. Gurau, and R. D. Rogers, "Ionic liquid processing of cellulose," Chemical Society Reviews, vol. 41, no. 4, pp. 15191537, 2012.

[2] M. Mora-Pale, L. Meli, T. V. Doherty, R. J. Linhardt, and J. S. Dordick, "Room temperature ionic liquids as emerging solvents for the pretreatment of lignocellulosic biomass," Biotechnology and Bioengineering, vol. 108, no. 6, pp. 1229-1245, 2011.

[3] J. Dupont, "On the solid, liquid and solution structural organization of imidazolium ionic liquids," Journal of the Brazilian Chemical Society, vol. 15, no. 3, pp. 341-350, 2004.

[4] M. Gericke, K. Schlufter, T. Liebert, T. Heinze, and T. Budtova, "Rheological properties of cellulose/ionic liquid solutions: from dilute to concentrated states," Biomacromolecules, vol. 10, no. 5, pp. 1188-1194, 2009.

[5] X. Chen, Y. Zhang, L. Cheng, and H. Wang, "Rheology of concentrated cellulose solutions in 1-butyl-3-methylimidazolium chloride," Journal of Polymers and the Environment, vol. 17, no. 4, pp. 273-279, 2009.

[6] F. Lu, J. Song, B.-W. Cheng, X.-J. Ji, and L.-J. Wang, "Viscoelasticity and rheology in the regimes from dilute to concentrated in cellulose 1-ethyl-3-methylimidazolium acetate solutions," Cellulose, vol. 20, no. 3, pp. 1343-1352, 2013.

[7] Z. Liu, H. Wang, Z. Li et al., "Characterization of the regenerated cellulose films in ionic liquids and rheological properties of the solutions," Materials Chemistry and Physics, vol. 128, no. 1-2, pp. 220-227, 2011.

[8] Z. Liu, H. Wang, Z. Li et al., "Rheological properties of cotton pulp cellulose dissolved in 1-butyl-3-methylimidazolium chloride solutions," Polymer Engineering and Science, vol. 51, no. 12, pp. 2381-2386, 2011.

[9] F. Lu, L. Wang, X. Ji, B. Cheng, J. Song, and X. Gou, "Flow behavior and linear viscoelasticity of cellulose 1-allyl-3- methylimidazolium formate solutions," Carbohydrate Polymers, vol. 99, pp. 132-139, 2014.

[10] R. Arin, M. Brodin, A. Boldizar, and G. Westman, “Thermal and viscoelastic properties of cellulosic gels with different ionic liquids and coagulation agents," BioResources, vol. 8, no. 2, pp. 2209-2221, 2013.

[11] C. Olsson, A. Idström, L. Nordstierna, and G. Westman, "Influence of water on swelling and dissolution of cellulose in 1-ethyl3-methylimidazolium acetate," Carbohydrate Polymers, vol. 99, pp. 438-446, 2014.

[12] B. D. Rabideau, A. Agarwal, and A. E. Ismail, "The role of the cation in the solvation of cellulose by imidazolium-based ionic liquids," Journal of Physical Chemistry B, vol. 118, no. 6, pp. 16211629, 2014.

[13] Z. Xiong, J. Gao, D. Zhang, and C. Liu, "Hydrogen bond network of 1-alkyl-3-methylimidazolium ionic liquids: a network theory analysis," Journal of Theoretical and Computational Chemistry, vol. 11, no. 3, pp. 587-598, 2012.

[14] H. Zhang, J. Wu, J. Zhang, and J. He, "1-Allyl-3-methylimidazolium chloride room temperature ionic liquid: a new and powerful nonderivatizing solvent for cellulose," Macromolecules, vol. 38, no. 20, pp. 8272-8277, 2005.

[15] H. He, H. Chen, Y. Zheng et al., "The hydrogen-bonding interactions between 1-ethyl-3-methylimidazolium lactate ionic liquid and methanol*," Australian Journal of Chemistry, vol. 66, no. 1, pp. 50-59, 2013.

[16] K. Kathirgamanathan, Modification of cellulose using ionic liquids [Doctoral thesis], University of Auckland, 2010. 
[17] F. Lu, B. Cheng, J. Song, and Y. Liang, "Rheological characterization of concentrated cellulose solutions in 1-allyl-3-methylimidazolium chloride," Journal of Applied Polymer Science, vol. 124, no. 4, pp. 3419-3425, 2012.

[18] H. Song, J. Zhang, Y. Niu, and Z. Wang, "Phase transition and rheological behaviors of concentrated cellulose/ionic liquid solutions," Journal of Physical Chemistry B, vol. 114, no. 18, pp. 6006-6013, 2010.

[19] M. Fitzpatrick, P. Champagne, and M. F. Cunningham, "Quantitative determination of cellulose dissolved in 1-ethyl-3-methylimidazolium acetate using partial least squares regression on FTIR spectra," Carbohydrate Polymers, vol. 87, no. 2, pp. 11241130, 2012.

[20] B. Fazio, A. Triolo, and G. di Marco, "Local organization of water and its effect on the structural heterogeneities in roomtemperature ionic liquid $/ \mathrm{H}_{2} \mathrm{O}$ mixtures," Journal of Raman Spectroscopy, vol. 39, no. 2, pp. 233-237, 2008.

[21] L. K. J. Hauru, M. Hummel, A. W. T. King, I. Kilpeläinen, and H. Sixta, "Role of solvent parameters in the regeneration of cellulose from ionic liquid solutions," Biomacromolecules, vol. 13, no. 9, pp. 2896-2905, 2012. 

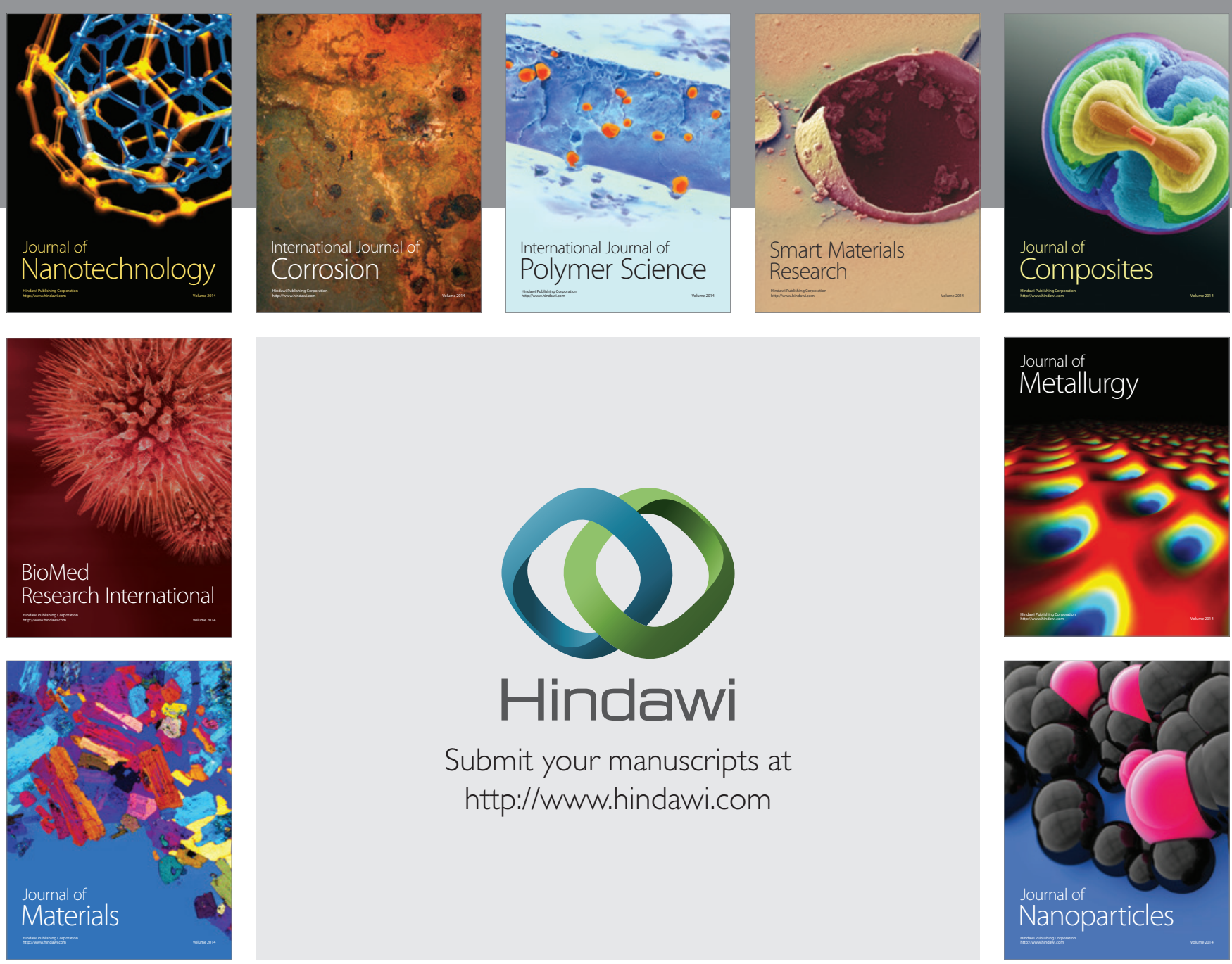

Submit your manuscripts at http://www.hindawi.com
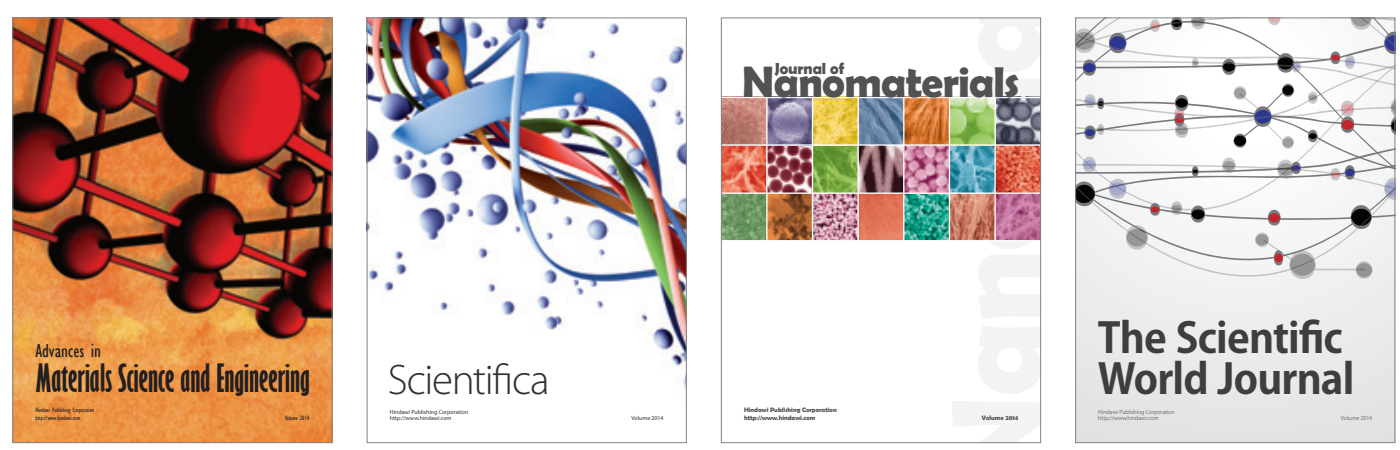

\section{The Scientific World Journal}
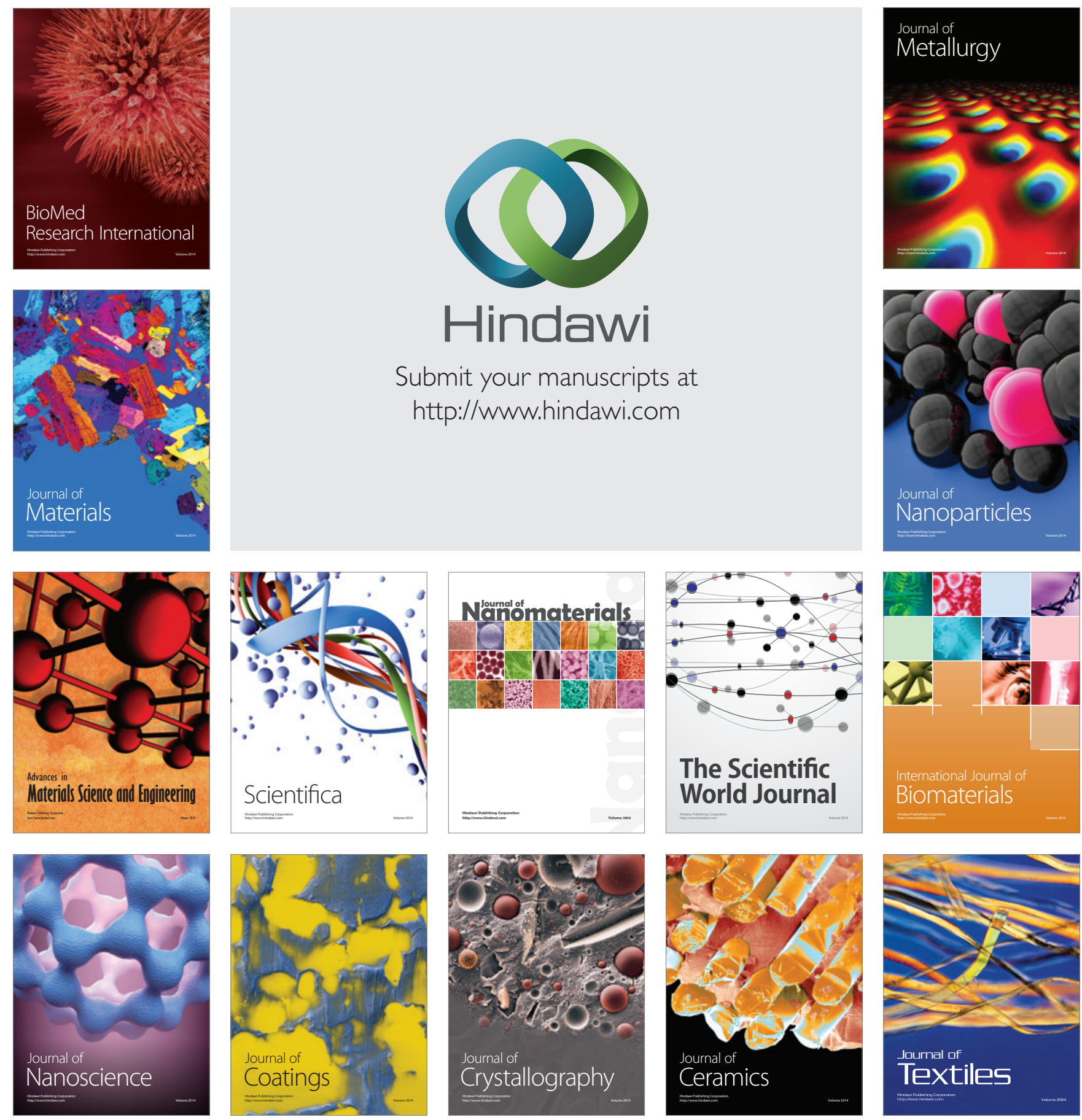